\title{
Fabrication of a Laser Welded Waterproof Coating Made of Stainless Steel Foil
}

\author{
Artúr Benjámin ACÉL, ${ }^{1}$ Márk WINDISCH, ${ }^{2}$ Anna MALOVECZKY ${ }^{3}$ \\ Bay Zoltán Nonprofit Ltd. for Applied Research. Budapest, Hungary \\ ${ }^{1}$ artur.acel@bayzoltan.hu \\ ${ }^{2}$ mark.windisch@bayzoltan.hu \\ 3 anna.maloveczky@bayzoltan.hu
}

\begin{abstract}
The purpose of this engineering design was to fabricate a waterproof coat for a carbon fibre reinforced polymer component. Austenitic stainless steel foil with $50 \mu \mathrm{m}$ thickness was used as the raw material. Deep-drawn elements that fit the geometry of the given part were welded together to form the coat. The deep drawing tools and the welding machine were self-designed and manufactured. The cutting of the blank and then the welding technology of the deep-drawn tablecloths were carried out with a TruMark 5010 marking laser made by Trumpf
\end{abstract}

Keywords: laser welding, stainless steel, thin foil, micro-welding.

\section{Introduction}

Currently, a trend can be observed in the development and application of increasingly compact and smaller-sized instruments. For this reason, there is a greater need for welding thin steel foils $(<100 \mu \mathrm{m})$. Several articles have been written on the implementation of low power laser beam welding of steel foils. [1, 2, 3]

Based on the welding results of thin films, we have developed a solution for the watertight coating of a carbon fibre reinforced automotive component. Considering the installation requirements, a $50 \mu \mathrm{m}$ thick stainless steel foil was used to form the watertight cover.

\section{Applied materials and methods}

Trumpf TruMark 5010 laser marking equipment was used to cut and weld the films. The solid-state resonator of the laser equipment had a pulse time of $250 \mathrm{~ns}$, an average power of $18.5 \mathrm{~W}$, a beam wavelength of $1064 \mathrm{~nm}$, a repetition frequency of $20 \mathrm{kHz}$ for cutting and $100 \mathrm{kHz}$ for welding.

Later, the average power of $18.5 \mathrm{~W}$ was used to determine the welding powers.

A Keyence VHX 2000 digital optical microscope was used to examine the cross section of the seams. The metallographic preparation of the seams was performed by sanding and polishing, followed by etching with royal water to show the fabric structure.

\section{Technological steps}

The carbon fibre reinforced plastic part to be covered was cylindrical and had a shoulder. Due to the geometry of the part, there were two possibilities for forming the cover. As a first solution, we designed 2 parts. One part was the cover of the cylindrical part, the other part was the shell and the flange. However, these two-part versions were discarded due to the poor deformation properties of the $50 \mu \mathrm{m}$ thick corrosion-resistant film. Due to the poor deformation property, the film is easily torn during shaping. As a second solution, three components were designed. In this case, we also kept the cover part, but we designed two parts to cover the mantle and the shoulder. To make the part, we needed tablecloths. These tablecloths were deep-drawn with the tools, and then the deep-drawn pieces were welded together using the welding device. 


\subsection{Cutting of blanks}

The cutting of the tablecloths was carried out using the TruTops Mark program of the laser beam equipment used.

AThe laser beam cutting power was determined at $18.5 \mathrm{~W}$ and the welding speed at $200 \mathrm{~mm} / \mathrm{s}$ in order to cut the film safely with the laser beam (sublimation cutting). The laser beam treatment was repeated ten times in succession on a sample at the same setting.

\subsection{Deep-drawn tools}

Due to the possible wrinkling of the plate during deep drawing (due to the design of the deep drawing tools), the size of the drawing gap was optimized for the appropriate clamping force. The centering of the discs was achieved with a $100 \mu \mathrm{m}$ shoulder prepared for this purpose. The tension and guide rings were bolted together.

The following parts were made from the tablecloths after deep drawing. Figure 3. shows the deep-drawn flange and Figure 4. shows the deepdrawn cover. Figure 5. shows the welded mantle.

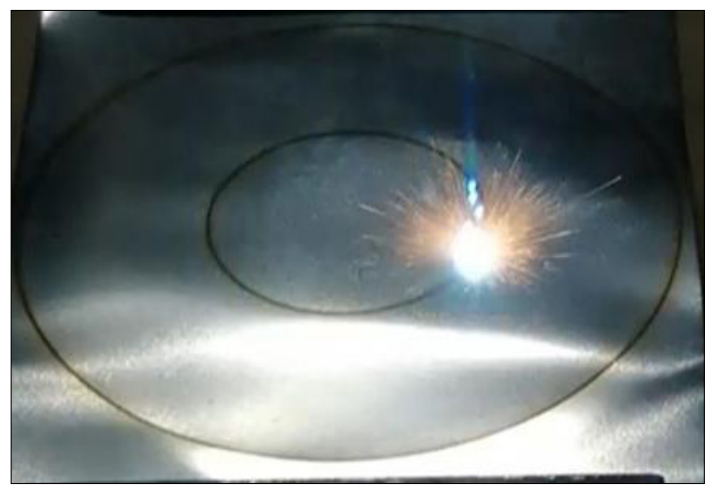

Figure 1. Blank cutting with TruMark 5010.

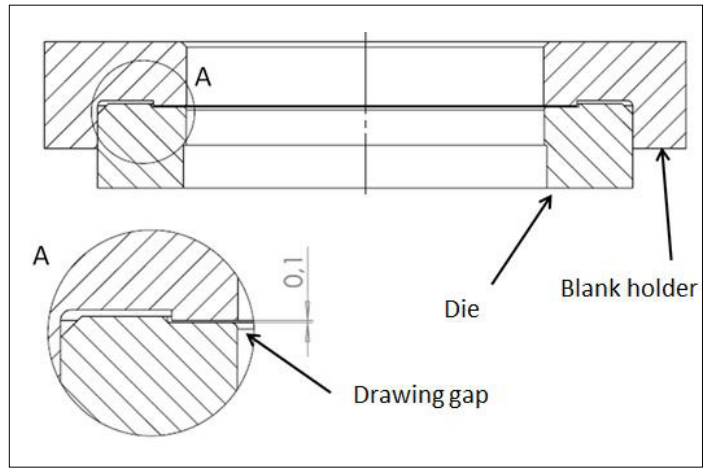

Figure 2. Sketch of a deep drawing tool.

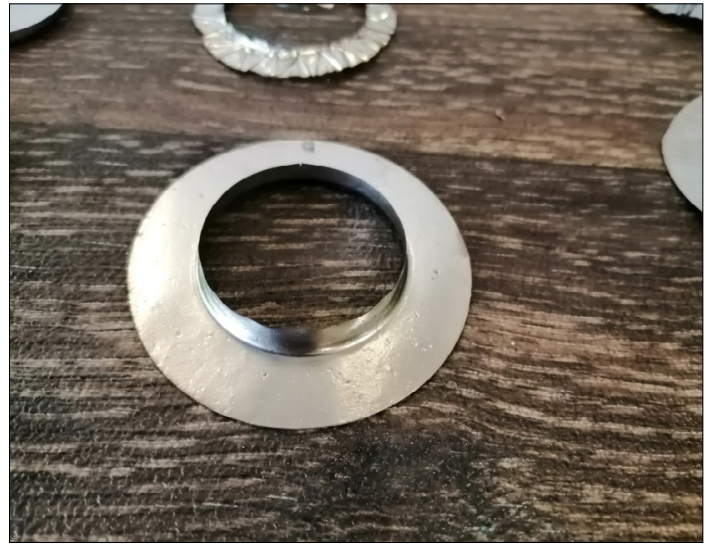

Figure 3. The successfully deep-drawn ring.

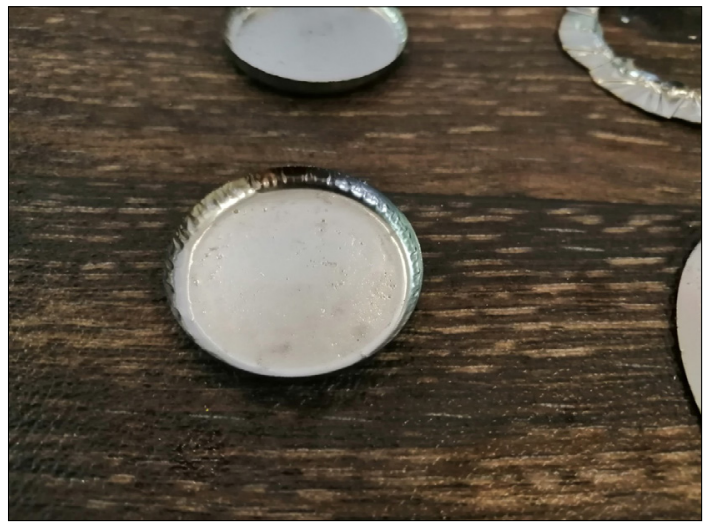

Figure 4. The successfully deep-drawn cover.

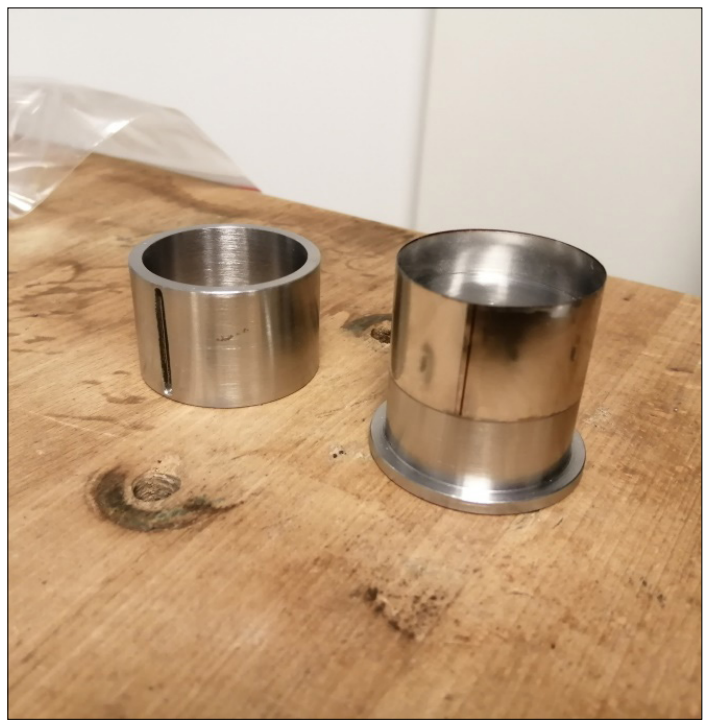

Figure 5. Successfully welded mantle with mantle welder fixture. 


\subsection{Welding}

Two devices were designed for welding the parts. With the help of one device, the seam of the mantle was formed, while with the other, the finished piece was welded together from the three parts. During welding, the average power of the laser beam was determined to be $16.65 \mathrm{~W}$ and the welding speed of $55 \mathrm{~mm} / \mathrm{s}$ to form the sheath seam. To form the seam of the cylinder shell, the average power of the laser beam was determined to be $17.58 \mathrm{~W}$ and the welding speed determined to be $55 \mathrm{~mm} / \mathrm{s}$. Figure 6 . shows the welding of the finished part.

\subsection{Presentation of formed seams}

Deep seam laser welding usually requires a socalled continuous laser beam. In our case, the laser beam equipment was pulsed. In order to make the laser beam as close as possible to continuous operation decoupling, we used the largest possible pulse mode of $100 \mathrm{kHz}$. In the series of experiments, the welding speed and the average power of the laser beam were optimized.

The optimum average power of the pulsed laser beam was found to be between $16.65 \mathrm{~W}$ and $17.58 \mathrm{~W}$. The welding speed was chosen to be $55 \mathrm{~mm} / \mathrm{s}$. Figure 7. shows the geometry of a weld welded with a laser power with an average power of $16.65 \mathrm{~W}$. The lack of material on the crown side is not relevant to the function of the seam. The overlapping thin films were fused to their full thickness by the laser beam. The cross-sectional shape of the seam made with a power of $17.58 \mathrm{~W}$ can be observed in Figure 8. In this case, like the crown side, the lack of material appears on the root side. Considering the total thickness of the films, the material fused.

\section{Conclusions}

With the Trumpf TruMark 5010 laser device, it was possible to cut out geometries with a defined geometry from a $50 \mu \mathrm{m}$ thick stainless steel foil. These placemats were formed with our own deep drawing tool. The deep-drawn parts were successfully welded together. The finished part is shown in Figure 10.

The water tightness of the finished parts is currently being tested. In the future, part of the test plan will be to increase seam overlap on the Trumpf TruMark 5010. A limitation of the further development of the technology is the lack of synchronous control of the laser beam coupling and the $\mathrm{CNC}$ rotary shaft.

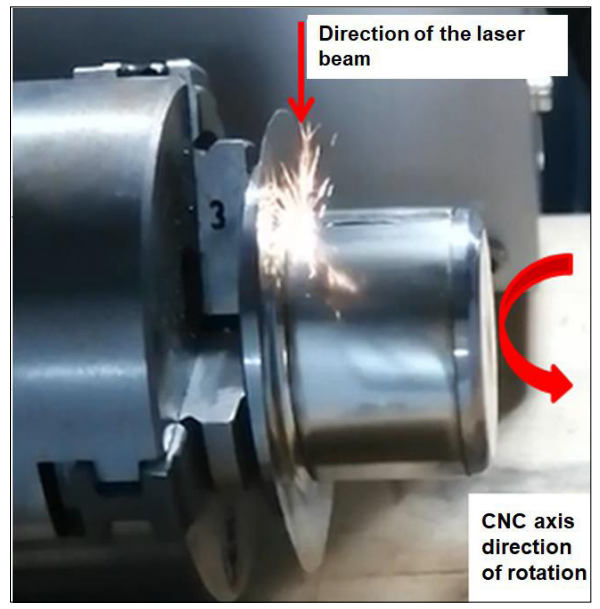

Figure 6. Circular seam welding of the mantle and flange.

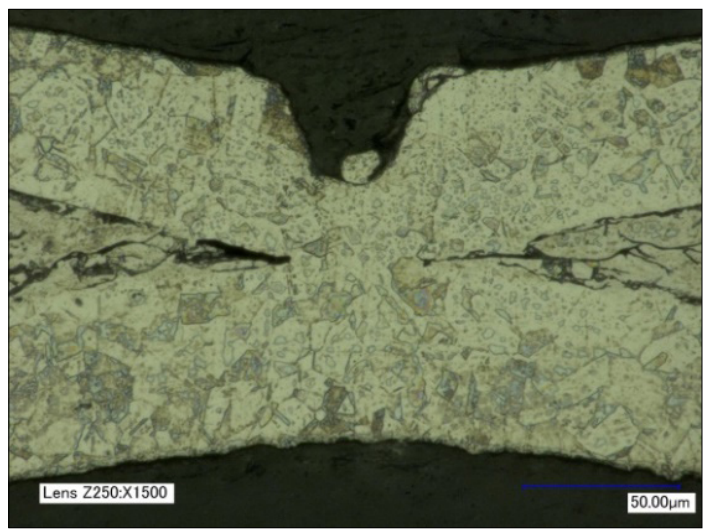

Figure 7. Sectional metallographic image of a seam created with a laser beam with an average power of $16.65 \mathrm{~W}$ and a welding speed of $55 \mathrm{~mm} / \mathrm{s}$.

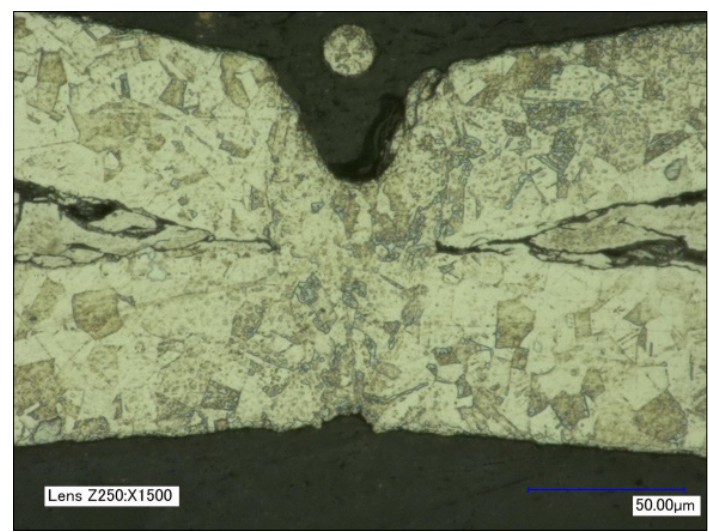

Figure 8. Sectional metallographic image of a seam created with a laser beam with an average power of $17.58 \mathrm{~W}$ and a welding speed of $55 \mathrm{~mm} / \mathrm{s}$. 


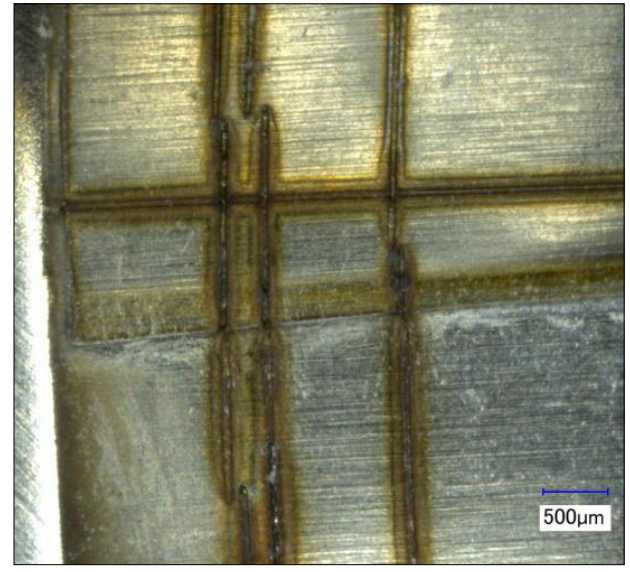

Figure 9. Weld seams at the overlap of the mantle and flange.

\section{Acknowledgments}

This research was supported by the European Union and the Hungarian State, co-financed by the European Regional Development Fund in the framework of the GINOP-2.2.1-15-2017- 00090 project, titled „E-mobility from Miskolc: Improvement of Coolant Pump and Engine Cooling Fan Taking into Account the Higher Quality Requirements in Electric Vehicles.

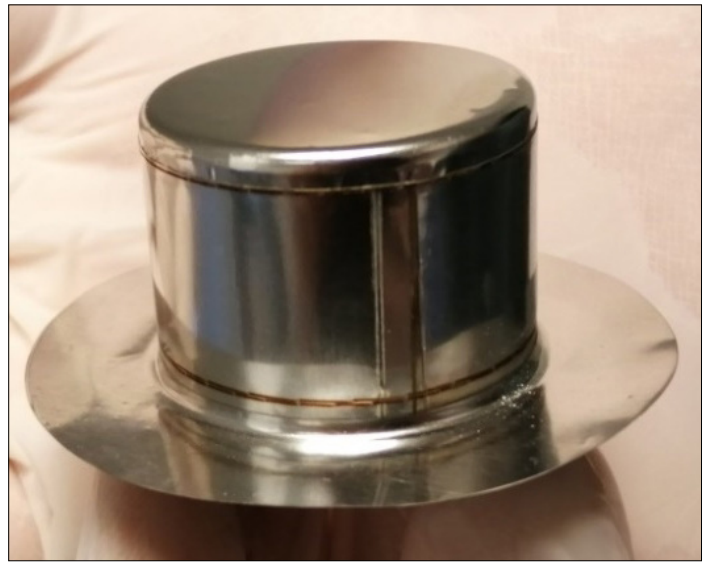

Figure 10. Waterproof cover with three seams.

\section{References}

[1] Pakmanesh M. R., Shamanian M.: Optimization of pulsed laser welding process parameters in order attain minimum underfill and undercut defects in thin 316L stainless steel foils. Optics and Laser Technology, 99. (2018) 30-38.

https://doi.org/10.1016/j.optlastec.2017.09.047

[2] Abe N., Funada Y., Imanaka T., Tsukamoto M.: Micro welding of thin stainless steel foil with a direct dioda laser. Transactions of JWRI, 34/1. (2005).

[3] Ventrellaa V. A., Berrettab J. R., Rossib W.: Pulsed Nd:YAG laser seam welding of AISI 316L stainless steel thin foils. Journal of Materials Processing Technology, 210/14. (2010) 1838-1843.

https://doi.org/10.1016/j.jmatprotec.2010.06.015 